\title{
Perbedaan Hasil Belajar Ekonomi dengan menggunakan Metode Pembelajaran Problem Posing dan Problem Solving di SMA Sriguna Palembang Tahun Pelajaran 2021/2022
}

\author{
Dian Meriyani ${ }^{1}$, Erma Yulaini ${ }^{2}$, Riswan Aradea ${ }^{3}$ \\ Universitas PGRI Palembang, Indonesia
}

$\triangle$ Corresponding author

[dianmeriyani22@gmail.com]

\begin{abstract}
Abstrak
Tujuan penelitian ini adalah untuk mengetahui perbedaan hasil belajar ekonomi dengan menggunakan metode pembelajaran problem posing dan problem solving di SMA Sriguna Palembang Tahun Pelajaran 2021/2022. Metode penelitian yang digunakan dalam penelitian adalah metode penelitian eksperimen komparatif yang bersifat membandingkan. Populasi dalam penelitian ini adalah seluruh siswa kelas XI IPS di SMA Sriguna Palembang Tahun Pelajaran 2021/2022 yang berjumlah 120 siswa, sedangkan sampel dalam penelitian ini adalah kelas IX IPS 1 dan 4 yang menggunakan teknik random sampling. Teknik pengumpulan data menggunakan dokumentasi, observasi dan tes, sedangkan teknik analisis data menggunakan uji t. Hasil penelitian menyatakan bahwa nilai rata-rata aktivitas belajar siswa kelas Problem Posing sebesar 85,18\% dengan kategori aktif, yang lebih besar dibandingkan nilai rata-rata aktivitas belajar siswa kelas Problem Solving sebesar 27,27\% dengan kategori aktif. Simpulan penelitian ini terdapat Perbedaan Hasil Belajar Ekonomi dengan menggunakan Metode Pembelajaran Problem Posing dan Problem Solving di SMA Sriguna Palembang Tahun Pelajaran 2021/2022.
\end{abstract}

Kata Kunci: Hasil belajar, Metode pembelajaran, Problem Posing, Problem Solving

\begin{abstract}
The purpose of this study was to determine the differences in economic learning outcomes using problem posing and problem solving learning methods at Sriguna Palembang High School in the $2021 / 2022$ academic year. The research method used in this research is a comparative experimental research method that is comparing. The population in this study were all students of class XI IPS at SMA Sriguna Palembang in the academic year 2021/2022, totaling 120 students, while the sample in this study was class IX IPS 1 and 4 using random sampling technique. Data collection techniques using documentation, observation and tests, while data analysis techniques using t-test. The results of stated that the average value of student learning activities in the Problem Posing class was $85.18 \%$ in the active category, which was greater than the average value for the learning activities of students in the Problem Solving class of $27.27 \%$ with the active category. It is concluded that there are differences in Economic Learning Outcomes using Problem Posing and Problem Solving Learning Methods at Sriguna Palembang High School in the 2021/2022 Academic Year.
\end{abstract}

Keywords: Learning Outcomes, Learning Methods, Problem Posing, Problem Solving

\section{PENDAHULUAN}

Keberhasilan suatu pendidikan salah satunya ditentukan oleh proses belajar mengajar itu berlangsung. Kegiatan belajar mengajar yang merupakan interaksi antara guru (mengajar) dan siswa (belajar) untuk mencapai suatu tujuan pembelajaran (Muliawan, 2016; Rusman, 2012). Guru dituntut untuk menciptakan suasana belajar mengajar yang efektif dan guru yang baik harus menyusun perencanaan pembelajaran sebelum melaksanakan kegiatan mengajar di kelas. Proses 
belajar mengajar yang baik harus didahulukan dengan persiapan yang baik (Aditya, 2016; Maesaroh, 2013). Guru dapat dikatakan berhasil dilihat dari keterampilan dan kemampuan dalam menjalankan tugas dan perannya, terutama dalam penguasaan dan mengembangkan materi pelajaran, menciptakan proses kegiatan belajar mengajar yang baik, serta mengevaluasi kegiatan dan hasil belajar siswa (Kunandar, 2014). Dalam melaksanakan tugas mengajar guru diharuskan untuk profesional dan lebih kreatif dalam menyajikan pembelajaran agar tujuan pembelajaran yang diharapkan dapat tercapai dengan baik (Sani, 2013).

Dalam setiap pembelajaran terdapat hasil belajar yang digunakan guru sebagai tolok ukur dalam mencapai suatu pendidikan. Pada kenyataannya tidak semua siswa dapat mencapai hasil belajar yang baik. Peran aktif siswa juga sangat diperlukan agar komunikasi guru dan siswa berjalan baik sehingga kesulitan siswa dalam pembelajaran dapat diselesaikan bersama-sama. Aktivitas siswa dipengaruhi oleh peran guru dan pemilihan metode mengajar yang tepat (Slameto, 2018; Shoimin, 2017; Marjuki, 2020).

Metode pembelajaran merupakan suatu upaya atau cara yang dilakukan oleh guru agar tujuan proses belajar mengajar pada siswa tercapai sesuai yang diharapkan (MKDP, 2011). Dalam penelitian ini peneliti menggunakan metode pembelajaran Problem Posing dan Problem Solving. Metode pembelajaran Problem Posing adalah metode pembelajaran yang mengharuskan siswa membuat pertanyaan sendiri atau memecahkan suatu soal menjadi pertanyaan-pertanyaan yang lebih sederhana. Dalam metode pembelajaran ini siswa ditekankan pada kegiatan merumuskan soal yang memungkinkan dapat meningkatkan kemampuan siswa dalam menyelesaikan soal. Metode pembelajaran Problem Solving adalah metode pembelajaran yang menuntut siswa untuk berfikir kritis dalam memecahkan suatu masalah atau kasus untuk diselesaikan.

Kedua metode pembelajaran tersebut mendorong siswa untuk menganalisis, berfikir kritis dan kreatif dalam membuat dan memecahkan masalah melalui kegiatan pembelajaran, agar hasil belajar yang didapatkan optimal dan sesuai dengan yang diharapkan.

Berdasarkan hasil wawancara yang dilakukan sebelum penelitian dengan guru mata pelajaran ekonomi di SMA Sriguna Palembang, diperoleh bahwa proses pembelajaran yang dilakukan oleh guru telah bervariatif (Sukirno, 2011). Namun, masih terdapat beberapa siswa yang belum berperan aktif pada saat proses pembelajaran berlangsung, sehingga hasil belajarnya kurang optimal. Asumsi yang peneliti berikan adalah apabila diajarkan dengan menggunakan metode pembelajaran problem posing dan problem solving, maka aktivitas belajar siswa menjadi lebih aktif sehingga hasil belajar yang didapat akan optimal.

Untuk mengatasi masalah tersebut, guru yang merupakan sebagai motivator dan fasilitator dalam pembelajaran harus meningkatkan keaktifan dan hasil belajar siswa. Melalui pembelajaran yang bervariasi atau penggunaan metode pembelajaran yang bervariasi diantaranya metode pembelajaran Problem Posing dan Problem Solving. Selain itu, berdasarkan hasil wawancara yang peneliti lakukan, dengan guru mata pelajaran ekonomi di SMA Sriguna Palembang belum pernah menerapkan metode pembelajaran problem posing dan problem solving. Oleh karena itu, perlunya dilakukan penelitian tentang perbedaan metode pembelajaran tersebut.

Berdasarkan uraian diatas, maka peneliti berkeinginan untuk melakukan penelitian tentang "Perbedaan Hasil Belajar Ekonomi dengan menggunakan Metode Pembelajaran Problem Posing dan Problem Solving di SMA Sriguna Palembang Tahun Pelajaran 2021/2022".

\section{METODE PENELITIAN}

Dalam penelitian ini yang digunakan yaitu Metode eksperimen komparatif dalam penelitian ini digunakan untuk mengetahui perbedaan hasil belajar ekonomi dengan metode pembelajaran problem posing dan problem solving dalam 2 kelompok eksperimen yang berbeda. Agar penelitian ini mencapai sasaran yang tepat dan memperoleh informasi yang selengkap-lengkapnya, maka teknik yang digunakan untuk mendapatkan data dari penelitian ini dilakukan dengan metode sebagai berikut.

Metode dokumentasi yaitu mencari data mengenai hal-hal atau variabel yang berupa catatan, transkrip, buku, surat kabar, majalah, prasasti, notulen rapat, lengger, agenda dsb, Arikunto (2013). Dalam penelitian ini peneliti memperoleh data berupa keadaan atau riwayat singkat 
sekolah, struktur organisasi sekolah, data guru dan data siswa, silabus, RPP SMA Sriguna Palembang Tahun Pelajaran 2021/2022 serta data-data lain yang mendukung.

Dengan menggunakan sistem pembelajaran daring, peneliti mengobservasi kegiatan pembelajaran siswa menggunakan aplikasi google meet. Observasi yang dilakukan dalam penelitian ini untuk melihat perbedaan pelaksanaan metode pembelajaran Problem Posing dengan Problem Solving serta untuk mengetahui keaktifan siswa selama kegiatan proses pembelajaran berlangsung.

Menurut Arikunto (2013) "tes adalah serentetan pertanyaan atau latihan serta alat lain yang digunakan untuk mengukur keterampilan, pengetahuan inteligensi, kemampuan atau bakat yang dimiliki oleh individu atau kelompok". Pada penelitian ini metode tes berupa soal pilihan ganda digunakan untuk melihat hasil belajar siswa pada mata pelajaran ekonomi yang menggunakan metode pembelajaran Problem Posing dengan Problem Solving. Dalam penelitian ini soal tes menggunakan google form, lalu akan diberikan kepada siswa berupa link google form.

Analisis data observasi yang dimaksud yaitu untuk mengukur tingkat presentase aktivitas siswa dalam proses pembelajaran yang dilakukan secara daring menggunakan aplikasi google meet. Dalam hal ini peneliti menganalisa hasil data observasi atau pengamatan yang dilihat melalui aktivitas belajar siswa selama proses pembelajaran daring berlangsung. Data lembaran observasi dianalisis dengan cara di checklist dari setiap indikator. Hasil observasi tersebut selanjutnya akan dihitung dengan menggunakan rumus sebagai berikut.

$$
N P=\frac{R}{S M} X 100 \quad \text { Purwanto (2013) }
$$

Hasil belajar ekonomi siswa kelas XI IPS 1 dan XI IPS 4 dilihat dari hasil tes siswa setelah proses pembelajaran daring berlangsung, tes berupa pilihan ganda sebanyak 20 soal. Hasil belajar yang dimaksud berupa nilai dari hasil tes tersebut, untuk mengetahui perbedaan antara hasil belajar ekonomi siswa menggunakan metode pembelajaran Problem Posing dan Problem Solving di SMA Sriguna Palembang Tahun Pelajaran 2021/2022.

\section{Uji Homogenitas}

Uji homogenitas data dapat dicari dengan menggunakan rumus sebagai berikut.

$$
F=\frac{\text { Varian terbesar }}{\text { Varian terkecil }} \quad \text { Riduwan (2012) }
$$

Dengan kriteria pengujian :

Taraf signifikan $(\alpha)=0,05$

Jika $\mathrm{F}_{\text {hitung }} \geq \mathrm{F}_{\text {tabel }}$ berarti tidak homogen

Jika $F_{\text {hitung }} \leq \mathrm{F}_{\text {tabel }}$ berarti homogen

\section{Uji Normalitas}

Sugiyono (2017) mengatakan bahwa teknik pengujian normalitas data dengan menggunakan Chi Kuadrat $\left(\chi^{2}\right)$ dilakukan dengan cara membandingkan kurve normal yang terbentuk dari data yang telah terkumpul dengan kurve normal baku/standar.

Langkah-langkah yang diperlukan sebagai berikut (Sugiyono, 2019).

1) Menentukan jumlah kelas interval.

2) Menentukan panjang kelas interval.

3) Menyusun ke dalam tabel distribusi frekuensi, sekaligus tabel penolong untuk menghitung harga Chi Kuadrat hitung.

4) Menghitung $f_{h}$ (frekuensi yang diharapkan).

5) Memasukkan harga - harga $\mathrm{f}_{\mathrm{h}}$ ke dalam tabel kolom $\mathrm{f}_{\mathrm{h}}$, sekaligus menghitung harga - harga $\left(f_{0}-f_{h}\right)^{2} \operatorname{dan} \frac{\left(f_{0}-f_{h}\right)^{2}}{f_{h}}$.

6) Membandingkan harga Chi Kuadrat hitung dengan Chi Kuadrat tabel.

Dengan kriteria pengujian menurut Riduwan (2012) sebagai berikut.

Jika $\chi^{2}$ hitung $\geq \chi^{2}$ tabel, maka distribusi data tidak normal

Jika $\chi^{2}$ hitung $\leq \chi^{2}$ tabel, maka distribusi data normal. 


\section{HASIL DAN PEMBAHASAN}

Data Hasil Observasi

Pada penelitian ini data observasi yang diamati melalui aplikasi Google Meet saat kegiatan pembelajaran daring berlangsung digunakan untuk melihat keaktifan/aktivitas siswa dalam proses belajar mengajar secara daring yang menggunakan metode pembelajaran Problem Posing dan Problem Solving. Data yang terlampir diambil melalui lembar observasi dan dianalisa dengan empat tahap, yaitu pertama dengan diberi tanda checklist pada lembar observasi disetiap deskriptor yang tampak, apabila tidak tampak tidak diberi tanda checklist. Kedua memberikan nilai skor dari hasil checklist yang ada. Ketiga menghitung nilai skor yang telah diperoleh menjadi nilai keaktifan. Keempat mengkonversikan nilai keaktifan yang diperoleh menjadi kategori sangat aktif, aktif, cukup aktif, kurang aktif dan sangat kurang aktif.

\section{Deskripsi Data Hasil Observasi Siswa Kelas Problem Posing}

Berdasarkan pembelajaran daring menggunakan aplikasi Google Meet yang dilakukan selama dua kali pertemuan diperoleh hasil observasi data aktivitas siswa kelas XI IPS 4 dengan nilai rata-rata pada setiap indikator. Dari lampiran hasil rata-rata keaktifan siswa didapat hasil presentase sebanyak $85,18 \%$ siswa yang dikategorikan Aktif dan sebanyak $14,81 \%$ siswa dikategorikan Cukup aktif, dengan perincian sebagai berikut.

\section{Tabel 1. Distribusi Frekuensi Hasil Observasi XI IPS 4}

\begin{tabular}{|c|c|c|c|c|}
\hline No & Interval Nilai & Frekuensi & Presentase (\%) & Keterangan \\
\hline 1 & $86-100$ & 0 & 0 & Sangat Aktif \\
\hline 2 & $71-85$ & 23 & 85,18 & Aktif \\
\hline 3 & $56-70$ & 4 & 14,81 & Cukup Aktif \\
\hline 4 & $41-55$ & 0 & 0 & Kurang Aktif \\
\hline 5 & $26-40$ & 0 & 0 & Sangat kurang \\
\hline Jumlah & & 27 & 100 & \\
\hline
\end{tabular}

\section{Deskripsi Data Hasil Observasi Siswa Kelas Problem Solving}

Berdasarkan pembelajaran daring yang dilakukan selama dua kali pertemuan diperoleh hasil observasi data aktivitas siswa kelas XI IPS 1 dengan nilai rata-rata pada setiap indikator. Dari lampiran hasil rata-rata keaktifan siswa didapat hasil presentase sebanyak $27,27 \%$ siswa yang dikategorikan Aktif dan sebanyak 72,72\% siswa dikategorikan Cukup aktif, dengan perincian sebagai berikut.

\section{Tabel 2. Distribusi Frekuensi Hasil Observasi XI IPS 1}

\begin{tabular}{|c|c|c|c|c|}
\hline No & Interval Nilai & Frekuensi & Presentase (\%) & Keterangan \\
\hline 1 & $86-100$ & 0 & 0 & Sangat Aktif \\
\hline 2 & $71-85$ & 9 & 27,27 & Aktif \\
\hline 3 & $56-70$ & 24 & 72,72 & Cukup Aktif \\
\hline 4 & $41-55$ & 0 & 0 & Kurang Aktif \\
\hline 5 & $26-40$ & 0 & 0 & Sangat kurang \\
\hline Jumlah & & 33 & 100 & \\
\hline
\end{tabular}

\section{Data Hasil Tes}

\section{Deskripsi Data Hasil Tes Siswa Kelas Problem Posing}

Berdasarkan hasil pemberian soal tes terhadap kelas Problem Posing (XI IPS 4) sebanyak 20 soal dalam bentuk pilihan ganda, maka didapat hasil rata-rata belajar siswa 80,74 dengan nilai tertinggi 90 dan nilai terendah 70 , dengan perincian sebagai berikut. 
Tabel 3. Distribusi Frekuensi Hasil Belajar XI IPS 4

\begin{tabular}{|c|c|c|c|c|}
\hline No & Interval Nilai & Frekuensi & Presentase (\%) & Keterangan \\
\hline 1 & $86-100$ & 2 & 7,40 & Baik sekali \\
\hline 2 & $71-85$ & 24 & 88,89 & Baik \\
\hline 3 & $56-70$ & 1 & 3,70 & Cukup \\
\hline 4 & $41-55$ & 0 & 0 & Kurang \\
\hline 5 & $<40$ & 0 & 0 & Sangat kurang \\
\hline Jumlah & & 27 & 100 & \\
\hline
\end{tabular}

\section{Deskripsi Data Hasil Tes Siswa Kelas Problem Solving}

Berdasarkan hasil pemberian soal tes terhadap kelas Problem Solving (XI IPS 1) sebanyak 20 soal dalam bentuk pilihan ganda, maka didapat hasil rata-rata belajar siswa 75,90 dengan nilai tertinggi 95 dan nilai terendah 50, dengan perincian sebagai berikut.

\section{Tabel 4. Distribusi Frekuensi Hasil Belajar XI IPS 1}

\begin{tabular}{|c|c|c|c|c|}
\hline No & Interval Nilai & Frekuensi & Presentase (\%) & Keterangan \\
\hline 1 & $86-100$ & 4 & 12,12 & Baik sekali \\
\hline 2 & $71-85$ & 16 & 48,48 & Baik \\
\hline 3 & $56-70$ & 13 & 39,39 & Cukup \\
\hline 4 & $41-55$ & 0 & 0 & Kurang \\
\hline 5 & $<40$ & 0 & 0 & Sangat kurang \\
\hline Jumlah & & 33 & 100 & \\
\hline
\end{tabular}

\section{Normalitas Data}

\section{Normalitas Data Kelas Problem Posing}

Normalitas data kelas problem posing dapat ditentukan dengan langkah-langkah berikut ini.

1) Jumlah kelas interval ditetapkan $=6$, yang disesuaikan dengan 6 bidang pada Kurve Normal Baku.

2) Panjang kelas $=\frac{\text { Data terbesar }- \text { Data terkecil }}{6 \text { (jumlah kelas interval })}$

Panjang kelas $=\frac{90-70}{6}=3,3$ dibulatkan menjadi 3

3) Penyusunan ke dalam table distribusi frekuensi

\begin{tabular}{|c|c|c|}
\hline No. & Interval kelas & $f_{o}$ \\
\hline 1 & $70-73$ & 1 \\
\hline 2 & $74-77$ & 7 \\
\hline 3 & $78-81$ & 8 \\
\hline 4 & $82-85$ & 9 \\
\hline 5 & $86-89$ & 0 \\
\hline 6 & $90-93$ & 2 \\
\hline \multicolumn{2}{|c|}{ Jumlah } & 27 \\
\hline
\end{tabular}

4) Menghitung $f_{h}$ (frekuensi yang diharapkan)
a) Baris pertama dari atas 2,27\% × $27=0,61$ dibulatkan 1
b) Baris kedua 13,53\% $\times 27=3,65$ dibulatkan 4
c) Baris ketiga 34,13\% $\times 27=9,21$ dibulatkan 9
d) Baris keempat 34,13\% $\times 27=9,21$ dibulatkan 9
e) Baris kelima 13,53\% x $27=3,65$ dibulatkan 4
f) Baris keenam 2,27\% $\times 27=0,61$ dibulatkan 1 
5) Memasukkan perhitungan $f_{h}$ ke dalam tabel, kemudian menghitung nilai $\left(f_{o}-f_{h}\right)^{2}$ dan $\frac{\left(f_{o}-f_{h}\right)^{2}}{f_{h}}$ yang merupakan nilai Chi Kuadrat hitung.

Tabel 5. Normalitas Data Kelas Problem Posing

\begin{tabular}{|c|c|c|c|c|c|}
\hline Interval & $f_{o}$ & $f_{h}$ & $f_{o}-f_{h}$ & $\left(f_{o}-f_{h}\right)^{2}$ & $\frac{\left(f_{o}-f_{h}\right)^{2}}{f_{h}}$ \\
\hline $70-73$ & 1 & 1 & 0 & 0 & 0 \\
\hline $74-77$ & 7 & 4 & 3 & 9 & 2,25 \\
\hline $78-81$ & 8 & 9 & -1 & 1 & 0,11 \\
\hline $82-85$ & 9 & 9 & 0 & 0 & 0 \\
\hline $86-89$ & 0 & 4 & -4 & 16 & 4 \\
\hline $90-93$ & 2 & 1 & 1 & 1 & 1 \\
\hline Jumlah & 27 & 28 & -1 & 27 & 7,36 \\
\hline
\end{tabular}

6) Membandingkan Chi Kuadrat hitung dengan Chi Kuadrat tabel. Dalam perhitungan pada tabel di atas di dapat Chi Kuadrat hitung $=7,36$ dan Chi Kuadrat tabel dengan derajat kebebasan $(\mathrm{dk})=5$. Berdasarkan tabel Chi Kuadrat bila $\mathrm{dk}=5$ dan kesalahan yang ditetapkan $=5 \%$, maka Chi Kuadrat tabel $=11,070$. Dari perhitungan tabel di atas dapat disimpulkan $\chi^{2}$ hitung $=7,36<\chi^{2}$ tabel $=11,070$, maka distribusi data hasil belajar siswa kelas Problem Solving dapat dinyatakan berdistribusi normal.

\section{Normalitas Data Kelas Problem Solving}

Normalitas data kelas problem solving dapat ditentukan dengan langkah - langkah berikut ini.

1) Jumlah kelas interval ditetapkan $=6$, yang disesuaikan dengan 6 bidang pada Kurve Normal Baku.

2) Panjang kelas $=\frac{\text { Data terbesar }- \text { Data terkecil }}{6 \text { (jumlah kelas interval })}$

Panjang kelas $=\frac{95-50}{6}=7,5$ dibulatkan menjadi 8

3) Penyusunan ke dalam table distribusi frekuensi

\begin{tabular}{|c|c|c|}
\hline No. & Interval kelas & $f_{o}$ \\
\hline 1 & $50-58$ & 1 \\
\hline 2 & $59-67$ & 5 \\
\hline 3 & $68-76$ & 11 \\
\hline 4 & $77-85$ & 12 \\
\hline 5 & $86-94$ & 3 \\
\hline 6 & $95-103$ & 1 \\
\hline \multicolumn{2}{|c|}{ Jumlah } & 33 \\
\hline
\end{tabular}

4) Menghitung $f_{h}$ (frekuensi yang diharapkan)

a) Baris pertama dari atas 2,27\% × $33=0,74$ dibulatkan 1

b) Baris kedua 13,53\% $\times 33=4,46$ dibulatkan 4

c) Baris ketiga $34,13 \% \times 33=11,26$ dibulatkan 11

d) Baris keempat 34,13\% × $33=11,26$ dibulatkan 11

e) Baris kelima 13,53\% $\times 33=4,46$ dibulatkan 4

f) Baris keenam 2,27\% × $33=0,74$ dibulatkan 1

5) Memasukkan perhitungan $f_{h}$ ke dalam tabel, kemudian menghitung nilai $\left(f_{o}-f_{h}\right)^{2}$ dan $\frac{\left(f_{o}-f_{h}\right)^{2}}{f_{h}}$ yang merupakan nilai Chi Kuadrat hitung. 
Tabel 6. Normalitas Data Kelas Problem Solving

\begin{tabular}{|c|c|c|c|c|c|}
\hline Interval & $f_{o}$ & $f_{h}$ & $f_{o}-f_{h}$ & $\left(f_{o}-f_{h}\right)^{2}$ & $\frac{\left(f_{o}-f_{h}\right)^{2}}{f_{h}}$ \\
\hline $50-58$ & 1 & 1 & 0 & 0 & 0 \\
\hline $59-67$ & 5 & 4 & 1 & 1 & 0,25 \\
\hline $68-76$ & 11 & 11 & 0 & 0 & 0 \\
\hline $77-85$ & 12 & 11 & 1 & 1 & 0,09 \\
\hline $86-94$ & 3 & 4 & -1 & 1 & 0,25 \\
\hline $95-103$ & 1 & 1 & 0 & 0 & 0 \\
\hline Jumlah & 33 & 32 & 1 & 3 & 1,4 \\
\hline
\end{tabular}

6) Membandingkan Chi Kuadrat hitung dengan Chi Kuadrat tabel. Dalam perhitungan pada tabel di atas di dapat Chi Kuadrat hitung $=1,4$ dan Chi Kuadrat tabel dengan derajat kebebasan $(\mathrm{dk})=5$. Berdasarkan tabel Chi Kuadrat bila $\mathrm{dk}=5$ dan kesalahan yang ditetapkan $=5 \%$, maka Chi Kuadrat tabel $=11,070$. Dari perhitungan tabel di atas dapat disimpulkan $\chi^{2}$ hitung $=1,4<\chi^{2}$ tabel $=11,070$, maka distribusi data hasil belajar siswa kelas Problem Posing dapat dinyatakan berdistribusi normal.

\section{Homogenitas Data}

Homogenitas data kelas problem posing dan problem solving dapat ditentukan dengan langkah - langkah berikut ini.

$$
\begin{array}{ll}
\sum x_{1}{ }^{2}=176700 & n_{1}=27 \\
\sum x_{2}{ }^{2}=193225 & n_{2}=33
\end{array}
$$

1) Menghitung standar deviasi hasil belajar siswa kelas problem posing

$$
\begin{array}{lll}
S=\sqrt{\frac{\sum x_{1}^{2}}{n_{1}-1}} & =\sqrt{\frac{176700}{27-1}} & =\sqrt{\frac{176700}{26}} \\
=\sqrt{6796,15} & & =82,43
\end{array}
$$

2) Menghitung standar deviasi hasil belajar siswa kelas problem solving

$$
\begin{aligned}
& S=\sqrt{\frac{\sum x_{2}^{2}}{n_{2}-1}} \quad=\sqrt{\frac{193225}{33-1}} \quad=77,70 \\
& =\sqrt{6038,28} \quad=\sqrt{\frac{193225}{32}}
\end{aligned}
$$

3) Menghitung nilai $F_{\text {hitung }}$

$\mathrm{F}=\frac{\text { Varian terbesar }}{\text { Varian terkecil }}=\frac{82,43}{77,70}=1,06$

4) Membandingkan nilai $F_{\text {hitung }}$ dengan nilai $F_{\text {tabel }}$ dengan db pembilang (27-1) dan db penyebut (33-1) dengan taraf signifikan 5\%, maka diperoleh $F_{\text {tabel }}=1,86$

\section{Pembahasan}

Berdasarkan hasil observasi diatas maka, presentase keaktifan siswa kelas Problem Posing sebesar 85,18\% dengan kategori aktif sedangkan kelas Problem Solving sebesar 27,27\% dengan kategori aktif. Jadi dapat disimpulkan kelas Problem Posing memiliki siswa yang lebih aktif dibandingkan dengan kelas Problem Solving.Berdasarkan data perhitungan hasil observasi keaktifan siswa kelas Problem Posing diperoleh presentase sebanyak 85,18\% siswa yang dikategorikan Aktif. Sedangkan hasil observasi keaktifan siswa kelas Problem Solving diperoleh presentase sebanyak $27,27 \%$ siswa yang dikategorikan Aktif. Perbedaan keaktifan siswa yang signifikan antara siswa yang diajarkan dengan metode pembelajaran Problem Posing dan siswa yang diajarkan dengan 
metode pembelajaran Problem Solving, maka dapat disimpulkan kelas Problem Posing memiliki siswa yang lebih aktif dibandingkan dengan kelas Problem Solving.

Berdasarkan data perhitungan hasil belajar siswa diperoleh bahwa kelas Problem Posing mendapatkan nilai rata-rata tertinggi sebesar 80,74 yang dikategorikan baik sekali dan kelas Problem Solving mendapatkan nilai rata-rata yang lebih rendah sebesar 75,90 yang dikategorikan baik. Berdasarkan hasil perhitungan pengujian hipotesis di atas di dapat $t_{\text {hitung }}=2,095$ dan $t_{\text {hitung }}$ dengan $\mathrm{dk}=n_{1}+n_{2}-2=33+27-2=58$, dan taraf kesalahan $=5 \%$, maka $t_{\text {tabel }}=2,002$. Dari perhitungan di atas dapat disimpulkan $t_{\text {hitung }}=2,095>t_{\text {tabel }}=2,002$, dengan demikian dapat disimpulkan bahwa Ha diterima dan Ho ditolak yang berarti terdapat perbedaan hasil belajar ekonomi dengan menggunakan metode pembelajaran Problem Posing dan Problem Solving. Namun perbedaan antara nilai rata-rata hasil belajar siswa dan perhitungan pengujian hipotesis tidak terlalu nyata, dikarenakan selisih nilai rata-rata hasil belajar antara kedua metode tidak terlalu jauh dan selisih antara perhitungan $t_{\text {hitung }}$ dan $t_{\text {tabel }}$ tidak terlalu besar.

Berdasarkan hasil penelitian yang dilakukan peneliti di SMA Sriguna Palembang Tahun Pelajaran 2021/2022 memberikan informasi bahwa terdapat perbedaan hasil belajar ekonomi dengan menggunakan metode pembelajaran Problem Posing dan Problem Solving, perbedaan tersebut dapat disebabkan oleh adanya perbedaan perlakuan dan langkah-langkah dalam kegiatan pembelajaran (Harefa, 2020). Dalam penelitian ini metode pembelajaran Problem Posing lebih baik untuk meningkatkan hasil belajar siswa dibandingkan dengan metode pembelajaran Problem Solving. Hal tersebut juga didukung oleh beberapa kelebihan Menurut Nur (2020) dari metode pembelajaran Problem Posing, yaitu melatih kemampuan untuk menyelesaikan suatu masalah, menumbuhkan rasa percaya diri sebab masalah yang ditimbulkan berasal dari siswa itu sendiri dan meningkatkan pemahaman konsep pada siswa.

\section{KESIMPULAN}

Berdasarkan hasil penelitian dan pembahasan pada bab sebelumnya bahwa perbedaan hasil belajar ekonomi dengan menggunakan metode pembelajaran Problem Posing dan Problem Solving di SMA Sriguna Palembang Tahun Pelajaran 2021/2022, dapat disimpulkan bahwa pada data hasil belajar siswa kelas XI IPS 4 yang menggunakan metode pembelajaran Problem Posing memperoleh nilai rata-rata hasil belajar siswa sebesar 80,74 yang lebih tinggi dibandingkan siswa kelas XI IPS 1 yang menggunakan metode pembelajaran Problem Solving memperoleh nilai rata-rata hasil belajar siswa sebesar 75,90.

\section{DAFTAR PUSTAKA}

Aditya, D. Y. (2016). Pengaruh Penerapan Metode Pembelajaran Resitasi Terhadap Hasil Belajar Matematika Siswa. SAP, 1(2), 165 - 174.

Arikunto, S. (2013). Prosedur Penelitian Suatu Pendekatan Praktik. Jakarta: PT Rineka Cipta.

Harefa, D. (2020). Perbedaan Hasil Belajar Fisika Melalui Model Pembelajaran Problem Posing dan Problem Solving pada siswa kelas X-Mia SMA Swasta Kampus Telukdalam. Prosiding Seminar Nasional Sains, 1(1), 103 - 116.

Kunandar. (2014). Penilaian Autentik (Penilaian Hasil Belajar Peserta Didik Berdasarkan Kurikulum 2013). Jakarta: RajaGrafindo Persada.

Maesaroh, S. (2013). Peranan Metode Pembelajaran Terhadap Minat dan Prestasi Belajar Pendidikan Agama Islam. Kependidikan, 1(1), 150 - 168.

Marjuki. (2020). 181 Model Pembelajaran PAIKEM Berbasis Pendekatan Saintifik. Bandung: Remaja Rosdakarya.

MKDP, T. P. (2011). Kurikulum dan Pembelajaran. Jakarta: Raja Grafindo Persada.

Muliawan, J. U. (2016). 45 Model Pembelajaran Spektakuler. Yogyakarta: Ar-Ruzz.

Nur, I. T. (2018). Model Pembelajaran PPS (Problem Posing \& Solving). Sukabumi: CV Jejak.

Purwanto, N. (2013). Prinsip - prinsip \& Teknik Evaluasi Pengajaran. Bandung: Remaja Rosdakarya.

Riduwan. (2012). Dasar - dasar Statistika. Bandung: Alfabeta.

Rusman. (2012). Belajar dan Pembelajaran Berbasis Komputer. Bandung: Alfabeta. 
Sani, R. A. (2013). Inovasi Pembelajaran. Jakarta: Bumi Aksara.

Shoimin, A. (2017). 68 Model Pembelajaran Inovatif dalam Kurikulum 2013. Yogyakarta: Ar-Ruzz Media.

Slameto. (2018). Belajar dan Faktor - faktor yang Mempengaruhi. Jakarta: Rineka Cipta.

Sugiyono. (2017). Statistika untuk Penelitian. Bandung: Alfabeta.

Sugiyono. (2019). Metode Penelitian Pendidikan (Kuantitatif, Kualitatif, Kombinasi, R\&D dan Penelitian Pendidikan). Bandung: Alfabeta.

Sukirno, S. (2011). Mikro Ekonomi Teori Pengantar Edisi Ketiga. Jakarta: PT Raja Grafindo Persada. 